Article

\title{
Identification and Quantification of a Toxigenic and Non-Toxigenic Aspergillus flavus Strain in Contaminated Maize Using Quantitative Real-Time PCR
}

\author{
J. Erik Mylroie ${ }^{1, *}$, Seval Ozkan ${ }^{2}$, Renuka Shivaji ${ }^{3}$, Gary L. Windham ${ }^{1}$, Michael N. Alpe ${ }^{1}$ and \\ W. Paul Williams ${ }^{1}$
}

Received: 26 October 2015; Accepted: 28 December 2015; Published: 4 January 2016

Academic Editor: Shohei Sakuda

1 United States Department of Agriculture, Agricultural Research Service, Corn Host Plant Resistance Research Unit, Mississippi State City, MS 39762, USA; gary.windham@ars.usda.gov (G.L.W.); mnalpe@landolakes.com (M.N.A.); paul.williams@ars.usda.gov (W.P.W.)

2 Department of Plant and Soil Sciences, Mississippi State University, Mississippi State City, MS 39762, USA; so35@pss.msstate.edu

3 University of North Carolina at Greensboro Molecular Core Lab, University of North Carolina at Greensboro, Greensboro, NC 27412, USA; r_shiva2@uncg.edu

* Correspondence: erik.mylroie@ars.usda.gov; Tel.: +1-662-325-8023; Fax: +1-662-325-8441

\begin{abstract}
Aflatoxins, which are produced by Aspergillus flavus, are toxic to humans, livestock, and pets. The value of maize (Zea mays) grain is markedly reduced when contaminated with aflatoxin. Plant resistance and biological control using non-toxin producing strains are considered effective strategies for reducing aflatoxin accumulation in maize grain. Distinguishing between the toxin and non-toxin producing strains is important in determining the effectiveness of bio-control strategies and understanding inter-strain interactions. Using polymorphisms found in the fungal rRNA intergenic spacer region (IGS) between a toxigenic strain of A. flavus (NRRL 3357) and the non-toxigenic strain used in the biological control agent Afla-Guard ${ }^{\circledR}$ (NRRL 21882), we developed a set of primers that allows for the identification and quantification of the two strains using quantitative PCR. This primer set has been used to screen maize grain that was inoculated with the two strains individually and co-inoculated with both strains, and it has been shown to be effective in both the identification and quantification of both strains. Screening of co-inoculated ears from multiple resistant and susceptible genotypic crosses revealed no significant differences in fungal biomass accumulation of either strain in the field tests from 2010 and 2011 when compared across the means of all genotypes. Only one genotype/year combination showed significant differences in strain accumulation. Aflatoxin accumulation analysis showed that, as expected, genotypes inoculated with the toxigenic strain accumulated more aflatoxin than when co-inoculated with both strains or inoculated with only the non-toxigenic strain. Furthermore, accumulation of toxigenic fungal mass was significantly correlated with aflatoxin accumulation while non-toxigenic fungal accumulation was not. This primer set will allow researchers to better determine how the two fungal strains compete on the maize ear and investigate the interaction between different maize lines and these $A$. flavus strains.
\end{abstract}

Keywords: aflatoxin; Aspergillus flavus; PCR; quantification; maize; corn 


\section{Introduction}

Aflatoxin is a toxic and carcinogenic secondary metabolite produced by Aspergillus flavus during infection of maize and other crops [1,2]. Due to its harmful nature, aflatoxin contamination levels in maize grain are tightly regulated by the FDA, and grain that exceeds set limits results in an economic loss for maize producers [3]. Thus, efforts have been made to reduce aflatoxin accumulation in maize grain through avenues such as detoxification, biological control, and host plant resistance. Breeding programs have been successful in developing resistant maize germplasm such as Mp313E, Mp715, Mp719, and Tex6 [4-8]. Biological control agents, such as Afla-Guard ${ }^{\circledR}$ and AF36 ${ }^{\circledR}$, have been shown to reduce aflatoxin contamination in maize [9-15].

A combined effort that includes the use of resistant maize genotypes and a biological control agent shows promise as an effective strategy in combating aflatoxin accumulation. Therefore, it is important to better understand the interaction between maize and both toxigenic and non-toxigenic Aspergillus flavus strains. Studies have shown that a positive correlation exists between the total fungal biomass and aflatoxin accumulation [16-18]. Furthermore, recent research has shown that when maize ears were co-inoculated with a toxigenic and non-toxigenic strain that there was significantly less aflatoxin accumulation than in ears only inoculated with a toxigenic strain [13]. To better understand the interaction between maize, toxigenic $A$. flavus, and non-toxigenic $A$. flavus, a method to quantify each strain of the fungus from infected ears is necessary. There have been many studies which have developed tools to successfully differentiate between or quantify Aspergillus species as well as toxigenic and non-toxigenic A. flavus strains [16,19-26]. However, at the time of this research there was no tool available to simultaneously identify and quantify the different strains of $A$. flavus from co-inoculated ears.

Aspergillus flavus strain NRRL 21882 lacks the entire aflatoxin gene pathway [27]. Therefore, the genes in the aflatoxin pathway, which have been used to identify and quantify $A$. flavus in previous studies, would not have been useful in this experiment. The rRNA gene cluster was thus chosen as a target area due to its high copy number and variability and due to its use in previous studies to quantify and identify A. flavus and other fungi in the genus Aspergillus [16,19-26,28-30].

The goal of this study was to find polymorphisms in the fungal rRNA gene region between a toxigenic (NRRL 3357) and a non-toxigenic (NRRL 21882) strain of $A$. flavus to develop a set of primers that allows for the identification and quantification of a toxigenic and non-toxigenic strain of $A$. flavus using qPCR. A. flavus NRRL 21882 was chosen for the non-toxigenic strain because it is the strain that is used as the active ingredient in the commercial biological control agent Afla-Guard ${ }^{\circledR}$ (Syngenta Crop Protection; Greensboro, NC, USA) [31]. After development, the effectiveness of these primers was tested in both laboratory and field experiments to validate their ability to identify and individually quantify the two fungal strains under co-inoculated conditions. Aflatoxin accumulation was analyzed on all treatments and genotypes to examine the effects of co-inoculation on aflatoxin accumulation.

\section{Results}

\subsection{Sequencing, Primer Design, and Primer Verification}

Segments of the $A$. flavus rRNA gene complex were sequenced to find polymorphisms that could be used to design primers able to distinguish between NRRL 3557 and NRRL21882. Sequencing using the primers ITS1 and ITS4 revealed no usable polymorphisms in the internal transcribed spacer (ITS) region and therefore the Intergenic spacer (IGS) region was sequenced. Sequencing of the IGS region using the primers LR12R and INVSR1R revealed multiple polymorphisms (Figure 1). A 2-base pair indel between NRRL 3357 and 21882 was used to design primer pairs which amplified an approximately $51 \mathrm{bp}$ fragment (Table 1, Figure 2). 
3357

21882

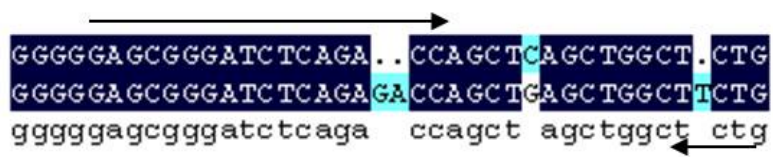

ATCACCCTACCTCCTACATAGTACCACCGACATCGCTTGG

A TCACCCTACC TCCTACATAGTACCACCGACATCGCTTGG

atcacectace tectacatagtaccacegacategettgg

Figure 1. Alignment of section of the IGS region of the rRNA gene complex in A. flavus between strain NRRL 3357 and 21882. Alignment shows $2 \mathrm{bp}$ indel used for strain specific primer development as well as other polymorphisms.

Table 1. Primers used for total fungal quantification and strain specific fungal quantification.

\begin{tabular}{ccc}
\hline Primer Name & Sequence $\left(\mathbf{5}^{\prime} \rightarrow \mathbf{3}^{\prime}\right)$ & Amplicon Size \\
\hline Af2-F $^{\mathrm{a}}$ & ATCATTACCGAGTGTAGGGTTCCT & $73 \mathrm{bp}$ \\
Af2-R & GCCGAAGCAACTAAGGTACAGTAAA & \\
\hline $3357-\mathrm{F} 2$ & GGAGCGGGATCTCAGACC & \\
$3357-\mathrm{R} 8$ & GTAGGAGGTAGGGTGATCAGAGC & $51 \mathrm{bp}$ \\
$21882-\mathrm{F} 2{ }^{\mathrm{b}}$ & GGAGCGGGATCTCAGAGAC &
\end{tabular}

a Primer pair originally published by Mideros et al. 2009 [16]; ${ }^{\text {b }}$ Uses the common reverse primer 3357-F8.

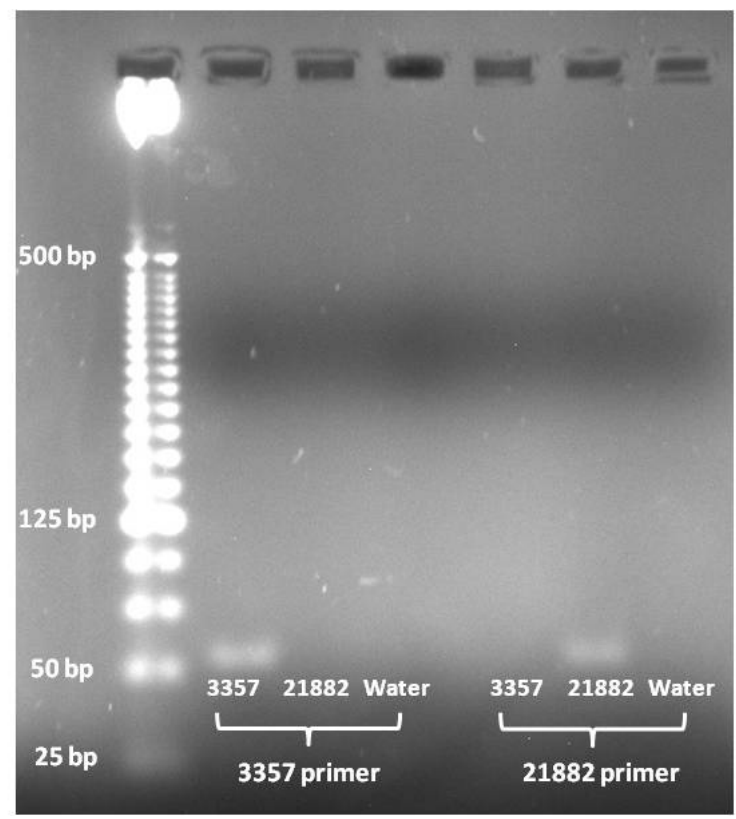

Figure 2. PCR products from A. flavus strain specific primers. Lanes contain as follows from left to right: Invitrogen 25 bp ladder, 3357 amplified with 3357 primer pair, 21882 amplified with 3357 primer pair, (-) control amplified with 3357 primer pair, 3357 amplified with 21882 primer pair, 21882 amplified with 21882 primer pair, and (-) control amplified with 21882 primer pair.

PCR amplification using the 3357 primer pair showed that it only amplified the target fragment in 3357 DNA and not in 21882 or the (-) control (Figure 2). Likewise, the 21882 primer pair only amplified the target fragment in 21882 DNA and not in 3357 or the (-) control (Figure 2).

\section{2. $q P C R$ Verification}

Since the primer pairs successfully demonstrated strain specificity in the PCR tests, the primer pairs were then tested for their efficacy in quantifying the two fungal strains in qPCR conditions and 
chemistry. An artificial mixed sample test was designed to determine how well the two primer pairs could quantify the two target fungal strains in a mixed sample. The first test was performed using $1 \mathrm{ng} / \mu \mathrm{L}$ of total fungal DNA using 2 test mixtures containing $60 \%$ and $40 \%$ of each fungal strain and screened using the primers for total fungus (Af2-F \& R), 3357 (3357F-2 \& 3357R-8), and 21882 (21882F-2 \& 3357R-8). Quantification using the Af2 primer pair showed that both mixtures contained a concentration of $1.05 \mathrm{ng} / \mu \mathrm{L}$ of total fungal DNA. In the mixture that contained $60 \% 3357$ and $40 \%$ 21882 , quantification showed that the sample contained $0.58 \mathrm{ng} / \mu \mathrm{L}$ of $3357 \mathrm{DNA}$ and $0.45 \mathrm{ng} / \mu \mathrm{L}$ of 21882 DNA. The quantification values for the inverse mixture were $0.43 \mathrm{ng} / \mu \mathrm{L}$ of $3357 \mathrm{DNA}$ and $0.65 \mathrm{ng} / \mu \mathrm{L}$ of $21882 \mathrm{DNA}$ (Table 2).

The second test was exactly the same as the first test but was performed using $0.1 \mathrm{ng} / \mu \mathrm{L}$ of total fungal DNA in the 2 test mixtures. Quantification using the Af2 primer pair showed that both mixtures contained a concentration of $0.1 \mathrm{ng} / \mu \mathrm{L}$ of total fungal DNA over the 2 mixtures. In the mixture that contained $60 \% 3357$ and $40 \% 21882$, quantification showed that the sample contained $0.06 \mathrm{ng} / \mu \mathrm{L}$ of $3357 \mathrm{DNA}$ and $0.039 \mathrm{ng} / \mu \mathrm{L}$ of $21882 \mathrm{DNA}$. The quantification values for the inverse mixture were $0.043 \mathrm{ng} / \mu \mathrm{L}$ of $3357 \mathrm{DNA}$ and $0.063 \mathrm{ng} / \mu \mathrm{L}$ of $21882 \mathrm{DNA}$ (Table 2).

Table 2. Quantification of artificially mixed samples of A. flavus strains NRRL 3357 and 21882 using qPCR. Strains were mixed in 60:40 ratios at total fungal concentrations of $1.0 \mathrm{ng} / \mu \mathrm{L}$ and $0.1 \mathrm{ng} / \mu \mathrm{L}$. The Roche LightCylcer ${ }^{\circledR} 480$ instrument (Roche Diagnostics GmbH, Mannheim, Germany) was used with the SYBR Master kit (Roche Diagnostics GmbH, Mannheim, Germany) and the strain specific primers for 3357 and 21882.

\begin{tabular}{|c|c|c|c|c|}
\hline \multirow{2}{*}{ Primer Pair } & $60 \% 3357$ & $60 \% 21882$ & $60 \% 3357$ & $60 \% 21882$ \\
\hline & $0.6 / 0.4(\mathrm{ng} / \mu \mathrm{L})$ & $0.6 / 0.4(\mathrm{ng} / \mu \mathrm{L})$ & 0.06/0.04 (ng/ $/ \mathrm{L})$ & 0.06/0.04 (ng/ $/ \mu \mathrm{L})$ \\
\hline 3357 & 0.575 & 0.428 & 0.06 & 0.0425 \\
\hline 21882 & 0.45 & 0.65 & 0.0399 & 0.0625 \\
\hline Af2 (Total) & 1.05 & 1.05 & 0.0955 & 0.1045 \\
\hline
\end{tabular}

\subsection{Fungal and Aflatoxin Quantification}

Analysis of variance showed significant differences between years, among genotypes and among treatments for both aflatoxin and A. flavus accumulation (Table 3). All interactions among main effects were significant for aflatoxin but none were significant for A. flavus accumulation (Table 3). For genotypes, fungal quantification revealed that in both the 2010 and 2011 field seasons, there were significant differences in total fungus accumulation among the genotypes tested (Table 4).

Table 3. Analysis of variance for aflatoxin and A. flavus accumulation in single cross hybrids from the Mississippi State, MS field location in 2010 and 2011.

\begin{tabular}{|c|c|c|c|}
\hline \multirow{2}{*}{ Source } & \multirow{2}{*}{$\mathrm{df}^{\mathrm{a}}$} & \multicolumn{2}{|c|}{ Mean Squares } \\
\hline & & Aflatoxin $b$ & A. flavus Accumulation ${ }^{\mathrm{c}}$ \\
\hline Years & 1 & $24.69 *$ & $5.30 \times 10^{-4 *}$ \\
\hline Reps (Years) & 8 & 1.29 & $8.40 \times 10^{-5}$ \\
\hline Genotype & 3 & 129.44 * & $2.40 \times 10^{-3 *}$ \\
\hline Genotype $\times$ Years & 3 & $15.49 *$ & $1.80 \times 10^{-4}$ \\
\hline Reps (Genotype $\times$ Years) & 24 & 0.78 & $2.00 \times 10^{-4}$ \\
\hline Treatment & 3 & $42.35 *$ & $1.20 \times 10^{-3 *}$ \\
\hline Treat $\times$ Year & 3 & $17.66^{*}$ & $1.00 \times 10^{-4}$ \\
\hline Treat $\times$ Genotype & 9 & $8.89 *$ & $2.50 \times 10^{-4}$ \\
\hline Treatment $\times$ Year $\times$ Genotype & 9 & $4.22 *$ & $1.80 \times 10^{-4}$ \\
\hline Error & 90 & 124.60 & $1.80 \times 10^{-2}$ \\
\hline
\end{tabular}

a $\mathrm{d} f=$ degrees of freedom. ${ }^{\mathrm{b}}$ Before statistical analysis, means were transformed $(\ln (y+1)$, where $y=$ aflatoxin concentration). Geometric means expressed in $\mathrm{ng} / \mathrm{g}$ are the result of a reverse transformation. ${ }^{\mathrm{c}}$ A. flavus accumulation measured as $\mathrm{ng} / \mu \mathrm{L}$ of DNA. * Significant at $\alpha=0.05$. 
Table 4. Least significant difference (LSD) analysis of fungal accumulation by single cross hybrid across all treatments from Mississippi State, MS field location in 2010 and 2011.

\begin{tabular}{ccc}
\hline Year & Hybrid & Mean Fungal Accumulation $(\mathbf{n g} / \mu \mathbf{L})$ \\
\hline \multirow{4}{*}{2010} & SC212M $\times$ T173 & $0.0207^{\mathrm{a}}$ \\
& GA209 $\times$ SC212M & $0.0199^{\mathrm{a}}$ \\
& Mp313E $\times$ Mo18W & $0.0047^{\mathrm{b}}$ \\
& Mp494 $\times$ Mp717 & $0.0031^{\mathrm{b}}$ \\
\hline \multirow{4}{*}{$\mathbf{2 0 1 1}$} & SC212M $\times$ T173 & $0.0144^{\mathrm{a}}$ \\
& GA209 $\times$ SC212M & $0.0115^{\mathrm{a}, \mathrm{b}}$ \\
& Mp494 $\times$ Mp717 & $0.0039^{\mathrm{b}, \mathrm{c}}$ \\
& Mp313E $\times$ Mo18W & $0.0029^{\mathrm{c}}$ \\
\hline
\end{tabular}

$\mathrm{a}, \mathrm{b}, \mathrm{c}$ Means followed by the same letter do not significantly differ at $\alpha=0.05$.

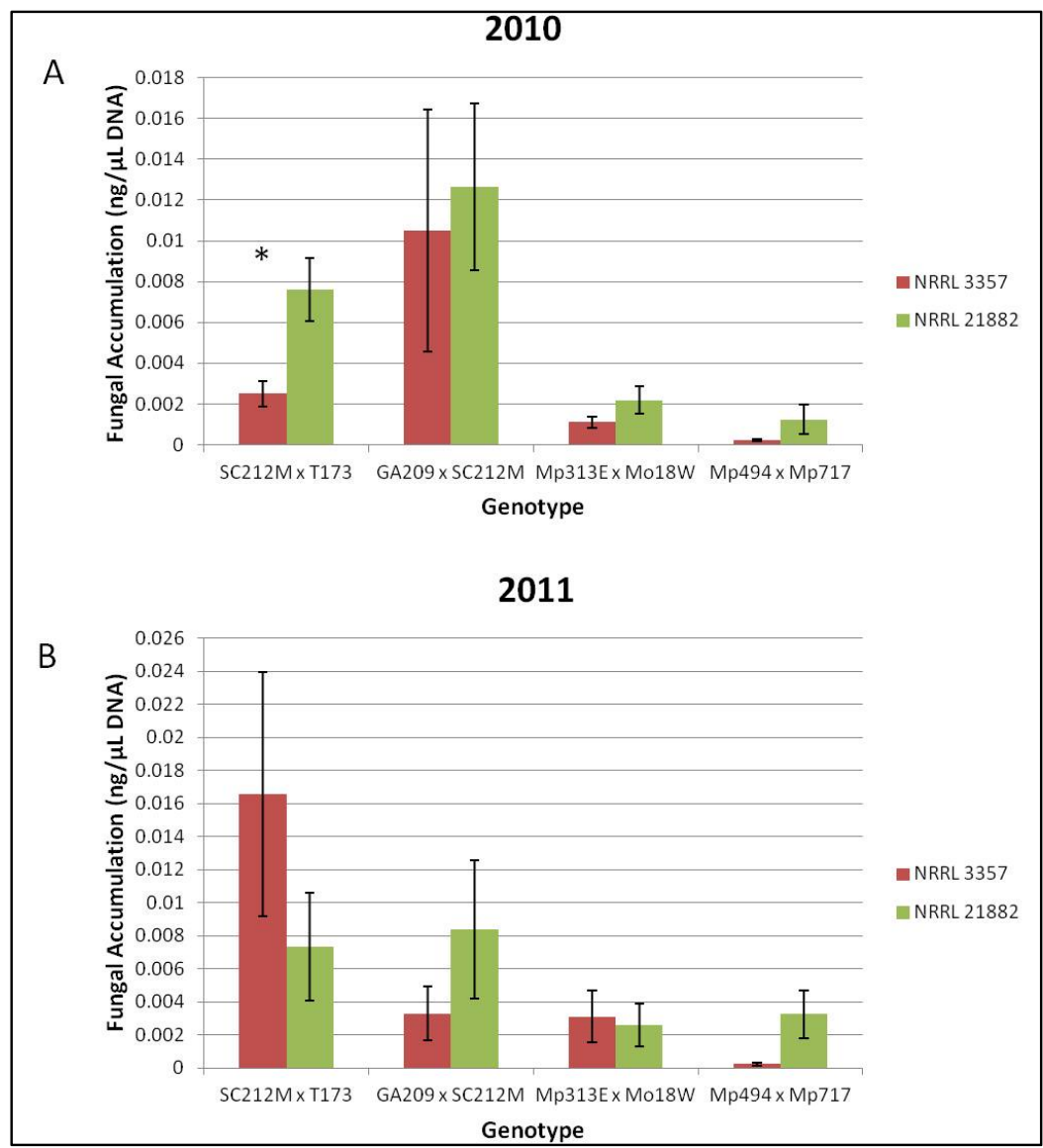

Figure 3. Fungal accumulation (ng/ $\mu \mathrm{L}$ ) of NRRL 3357 and 21882 in Co-Inoculated ears. (A) Fungal strain accumulation for each genotype for the field year 2010; (B) Fungal strain accumulation for each genotype for the field year 2011. * Indicates a significant difference $(\alpha=0.05)$ in A. flavus accumulation for strain NRRL 21882 or NRRL 3357 in the Co-Inoculated ears. Error bars represent one standard error.

Overall the resistant hybrids accumulated less total fungus than the susceptible hybrids. However, there were no significant differences among treatments in terms of total fungal accumulation when compared across all hybrids or when compared for each genotype/year combination. When the co-inoculated treatments were quantified using the strain specific primers it was found that neither strain of $A$. flavus was significantly more represented in co-inoculated samples for the means of each genotype in 2010 or 2011 . However, when each genotype/year combination was examined, the SC212M $\times$ T173 hybrid had significantly more A. flavus NRRL 21882 accumulation than NRRL 3357 
in the field year 2010 (Figure 3A). No other genotype/year combination had significant differences in strain accumulation (Figure 3A,B).

Aflatoxin quantification revealed that for both the 2010 and 2011 field seasons the resistant crosses accumulated significantly less aflatoxin than the susceptible crosses. The geometric means across all treatments for SC212M $\times$ T173, GA209 $\times$ SC212M, Mp494 $\times$ Mp717 and Mp313E $\times$ Mo18W were 35, 54, 13 , and $2 \mathrm{ng} / \mathrm{g}$ respectively in 2010 and 51, 80, 13, and $3 \mathrm{ng} / \mathrm{g}$ respectively in the field year 2011 (Table 5). Examination of the differences among the treatments showed that in almost all of the field years, co-inoculation reduced aflatoxin accumulation (Table 6). In regard to treatment across all genotypes, co-inoculation of the two strains reduced aflatoxin accumulation in both years but only significantly in 2010 (Table 7). Correlation for mean A. flavus NRRL 3357 fungal accumulation with mean aflatoxin accumulation for each genotype/year combination was highly correlated with an $R^{2}=0.79$ (Figure $4 \mathrm{~A}$ ); however, there was no correlation between mean NRRL 21882 fungal accumulation and aflatoxin accumulation $R^{2}=0.09$ (Figure 4B).

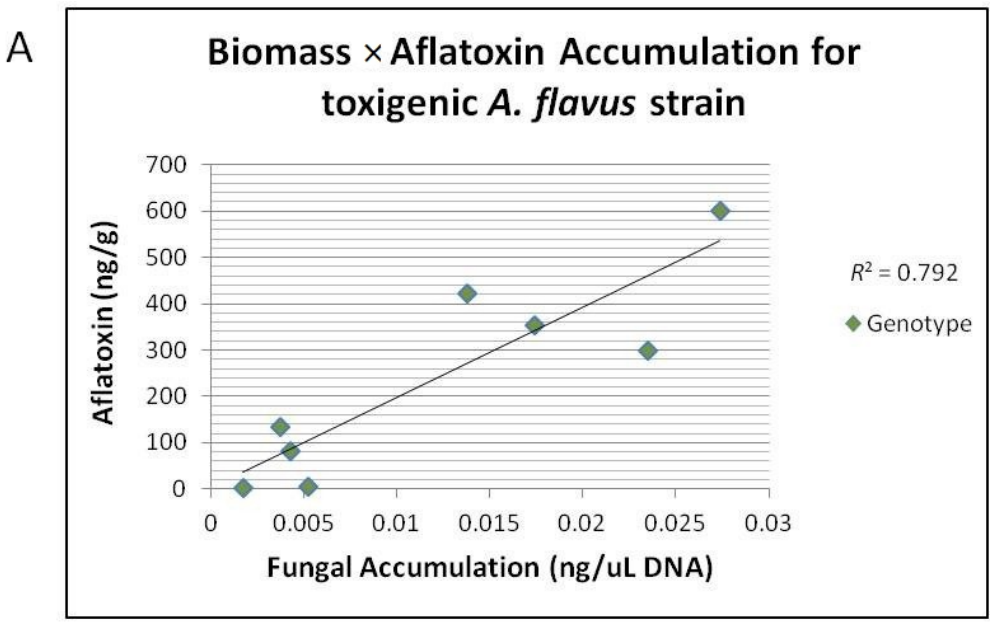

B

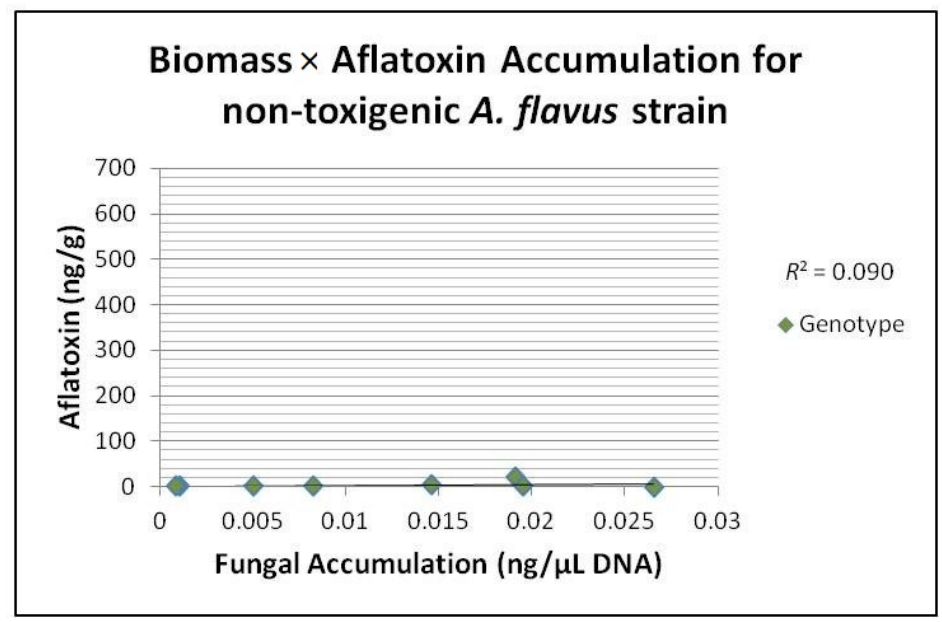

Figure 4. Correlation of mean A. flavus strain accumulation $(\mathrm{ng} / \mu \mathrm{L})$ to mean aflatoxin accumulation (ng/g). (A) Correlation of mean A. flavus strain 3357 fungal accumulation (ng/ $\mu \mathrm{L}$ ) to mean aflatoxin accumulation (ng/g) in ears for each genotype/year combination inoculated with 3357 or Co-Inoculated for field years 2010 and 2011. There was a strong correlation between 3357 accumulation and aflatoxin accumulation across all genotypes $\left(R^{2}=0.792\right)$; (B) Correlation of mean A. flavus strain 21882 fungal accumulation (ng/ $\mu \mathrm{L})$ to mean aflatoxin accumulation $(\mathrm{ng} / \mathrm{g})$ in ears of each genotype/year combination inoculated with 21882. There was a no correlation between 21882 accumulation and aflatoxin accumulation across all genotypes $\left(R^{2}=0.090\right)$. 
Table 5. Least significant difference (LSD) analysis of aflatoxin accumulation by single cross hybrid across all treatments from Mississippi State, MS field location in 2010 and 2011.

\begin{tabular}{ccc}
\hline \multirow{2}{*}{ Single Cross Hybrid } & \multicolumn{2}{c}{ Aflatoxin (ng/g) } \\
\cline { 2 - 3 } & $\mathbf{2 0 1 0}$ & $\mathbf{2 0 1 1}$ \\
\hline GA209 $\times$ SC212M & $54^{\mathrm{a}}$ & $80^{\mathrm{a}}$ \\
SC212M $\times$ T173 & $35^{\mathrm{a}}$ & $51^{\mathrm{a}}$ \\
Mp313E $\times$ Mo18W & $13^{\mathrm{b}}$ & $13^{\mathrm{b}}$ \\
Mp494 $\times$ Mp717 & $2^{\mathrm{c}}$ & $3^{\mathrm{c}}$ \\
\hline
\end{tabular}

Before statistical analysis, means were transformed $\left(\ln (y+1)\right.$, where $y=$ aflatoxin concentration). ${ }^{\mathrm{a}, \mathrm{b}, \mathrm{c}}$ Means followed by the same letter do not significantly differ at $\alpha=0.05$.

Table 6. Least significant difference (LSD) analysis of aflatoxin accumulation by single cross hybrid for each treatment and field year from Mississippi State, MS field location in 2010 and 2011.

\begin{tabular}{|c|c|c|c|c|c|c|c|c|}
\hline \multirow{4}{*}{ Treatment } & \multicolumn{8}{|c|}{ Single Cross Hybrid } \\
\hline & \multicolumn{2}{|c|}{$\mathrm{SC} 212 \mathrm{M} \times \mathrm{T} 173$} & \multicolumn{2}{|c|}{ GA209 $\times$ SC212M } & \multicolumn{2}{|c|}{ Mp313E $\times$ Mo18W } & \multicolumn{2}{|c|}{ Mp494 $\times$ Mp717 } \\
\hline & \multicolumn{8}{|c|}{ Aflatoxin (ng/g) } \\
\hline & 2010 & 2011 & 2010 & 2011 & 2010 & 2011 & 2010 & 2011 \\
\hline 3357 & $441^{\mathrm{a}}$ & $233^{a}$ & $931^{a}$ & $329^{a}$ & $115^{a}$ & $132^{\mathrm{a}}$ & $1^{\mathrm{a}}$ & $3^{a}$ \\
\hline Co-inoculated & $102^{b}$ & $422^{a}$ & $153^{b}$ & $92^{a, b}$ & $16^{\mathrm{b}}$ & $7^{b}$ & $1^{\mathrm{a}}$ & $4^{\mathrm{a}}$ \\
\hline 21882 & $0^{\mathrm{c}}$ & $2^{b}$ & $0^{\mathrm{c}}$ & $17^{b}$ & $1^{\mathrm{c}}$ & $0^{c}$ & $0^{\mathrm{a}}$ & $0^{\mathrm{a}}$ \\
\hline
\end{tabular}

Before statistical analysis, means were transformed $\left(\ln (y+1)\right.$, where $y=$ aflatoxin concentration). ${ }^{\mathrm{a}, \mathrm{b}, \mathrm{c}}$ Means followed by the same letter do not significantly differ at $\alpha=0.05$.

Table 7. Least significant difference (LSD) analysis of aflatoxin accumulation by treatments across all hybrids from Mississippi State, MS field location in 2010 and 2011.

\begin{tabular}{ccc}
\hline \multirow{2}{*}{ Treatment } & \multicolumn{2}{c}{ Aflatoxin (ng/g) } \\
\cline { 2 - 3 } & $\mathbf{2 0 1 0}$ & $\mathbf{2 0 1 1}$ \\
\hline 3357 & $103^{\mathrm{a}}$ & $77^{\mathrm{a}}$ \\
Co-inoculated & $38^{\mathrm{b}}$ & $33^{\mathrm{a}}$ \\
21882 & $1^{\mathrm{c}}$ & $2^{\mathrm{b}}$
\end{tabular}

Before statistical analysis, means were transformed $\left(\ln (y+1)\right.$, where $y=$ aflatoxin concentration). ${ }^{a, b, c}$ Means followed by the same letter do not significantly differ at $\alpha=0.05$.

\section{Discussion}

\subsection{Sequencing, Primer Design, and Primer Verification}

Previous studies have used genes in the aflatoxin pathway to identify and quantify toxigenic isolates of A. flavus as well as other Aspergillus species and other mycotoxin producing fungi [24,26]. However, since the non-toxin producing strain (NRRL 21882) has the entire aflatoxin producing pathway deleted, it was decided to use a different gene for fungal identification and quantification [27]. The rRNA genes were excellent candidates due to their high copy number and variability $[21,32]$. Based on these criteria, the ITS region was initially chosen for sequencing in order to find polymorphisms useful in primer development. Though used to differentiate among numerous Aspergillus species in the past and to quantify total A. flavus contamination [16,19-26,28-30], sequencing of the ITS region of the A. flavus rRNA gene showed no polymorphisms suitable for use in differentiating between NRRL 3357 and NRRL 21882. Therefore, the IGS region was chosen due to its being a region of even higher variability [32]. Multiple indels and SNPs were found between NRRL 3357 and NRRL 21882 and one 2 bp indel was chosen to design primers to differentiate between the two A. flavus strains (Figure 1). PCR amplification and visualization showed that the two primer 
pairs were successful at indentifying the target fungal strain while not producing a product in the non-target strain.

\section{2. $q P C R$ Verification}

The tests with artificial mixtures of NRRL 3357 and 21882 showed that the primer pair was successful in quantifying each strain in a mixed fungal sample. Quantification results from all of the mixed samples were very close to the 60:40 target ratios when measured (Figure 2). This was a very promising result and showed that the primer pairs could not only successfully quantify a sample composed of a mixture of the two fungal strains but also quantify a mixture with only small differences in concentration with good accuracy. Furthermore, the total fungal amount was near 1.0 and $0.1 \mathrm{ng} / \mu \mathrm{L}$ for the two tests, meaning that, as expected, the Af2 primer set amplified each strain in the mixed sample equally.

\subsection{Fungal and Aflatoxin Quantification}

Quantification of total fungus showed that in both 2010 and 2011, as expected, the susceptible hybrids (SC212M $\times$ T173 \& GA209 $\times$ SC212M) had more fungal contamination than the resistant hybrids (Mp313E $\times$ Mo18W \& Mp494 $\times$ Mp717). Furthermore, when compared across hybrids there was no significant difference in fungal accumulation among the treatments. Therefore, it can be assumed that under these conditions the genotypes resisted fungal growth at the same rate regardless of which strain was present. When the co-inoculated samples were tested for fungal accumulation using the strain-specific primers, neither strain was found to be significantly more represented than the other strain when compared across all genotypes, and only one genotype/year combination showed a significant difference in strain accumulation (Figure 3). These findings, however, do not confirm or refute the suspected mechanisms of biological control which include competitive exclusion of toxigenic strains by non-toxigenic strains [9,12,33-36] and intraspecific inhibition [37-41]. More testing in different environments with more genotypes of maize is necessary before any substantive conclusions can be drawn about the interaction between the two fungal strains once infection on the maize ear has occurred.

Aflatoxin quantification analysis showed that the resistant genotypes (Mp313E $\times$ Mo18W \& Mp494) accumulated significantly less aflatoxin than the susceptible genotypes (SC212M $\times$ T173 \& GA209 $\times$ SC212M) in both the 2010 and 2011 field years. Fungal accumulation and aflatoxin accumulation where highly correlated, as has been found in previous studies [16-18]. Furthermore, it was found that in almost all cases (within genotypes and across genotypes) co-inoculated samples accumulated significantly less aflatoxin than those inoculated only with A. flavus strain NRRL 3357. The results are consistent with previous research that shows that a biological control agent can be effective in reducing the amount of aflatoxin accumulation in maize ears that are co-infected with a toxigenic fungus $[9,13,33-41]$.

\section{Experimental Section}

\subsection{Fungal DNA Extraction and Sequencing}

For fungal DNA extraction, Aspergillus flavus NRRL 3357 and 21882 strains were grown in $100 \mathrm{~mL}$ of potato dextrose broth for 7 days at $28^{\circ} \mathrm{C}$ under agitation at $150 \mathrm{rpm}$. Fungal mycelia were collected via filtration using a Buchner funnel with Whatman ${ }^{\mathrm{TM}} 110 \mathrm{~mm}$ filter paper (GE Healthcare UK; Little Chalfont, Buckinghamshire, UK) then flash frozen in liquid nitrogen. Tissue samples were ground in liquid nitrogen using a mortar and pestle and DNA was extracted using a protocol adapted for volume from Patterson et al. [42].

The Internal transcribed spacer (ITS) and Intergenic spacer (IGS) segments of the A. flavus rRNA gene were sequenced in the strains NRRL 3357 and NRRL 21882 to identify polymorphisms that could be used to differentiate between the two strains. The ITS region was sequenced using the ITS1 and 
ITS4 primers and the IGS region was sequenced using LR12R and INVSR1R primers [32]. For the ITS and IGS regions, PCR amplification was carried out using $500 \mathrm{ng}$ of fungal genomic DNA as template in $50 \mu \mathrm{L}$ reactions with $2 \mathrm{mM} \mathrm{MgCl}, 0.2 \mathrm{mM}$ of each dNTP, $0.5 \mu \mathrm{M}$ of the forward and reverse primer and TaKaRa ExTaq DNA polymerase (TAKARA BIO INC.; Otsu, Shiga, Japan). The product was gel purified and was cloned into the TOPO vector using TOPO ${ }^{\circledR}$ TA Cloning ${ }^{\circledR}$ Kit (Life Technologies; Carlsbad, CA, USA). Plasmids with insert were purified from 6 colonies for each line and the insert was sequenced from both directions for all the purified plasmids. Sequencing was performed by the Iowa State DNA Facility (Ames, IA, USA). The sequences from both strains were aligned to look for sequence variations.

\subsection{Primer Development and Verification}

An insertion/deletion was found in the IGS region that could be used to design primers to differentiate between the two strains of $A$. flavus (Figure 1). Two primer pairs were developed to distinguish between A. flavus NRRL 3357 and 21882 using Primer3web software v 4.0.0 [43]. The primer pairs shared a common reverse primer, 3357R-8 and two unique forward primers 3357F-2 and 21882F-2 (Table 1). The primer pairs were verified using PCR with a reaction volume of $50 \mu \mathrm{L}$ that contained $1 \mu \mathrm{L}$ of template $(10 \mathrm{ng} / \mu \mathrm{L}), 1 \mu \mathrm{L} 10 \mathrm{mM}$ dNTP Mix, $5 \mu \mathrm{L}$ 10 $\times$ PCR Buffer (Sigma-Aldrich ${ }^{\circledR}$; St. Louis, MO, USA), $1 \mu \mathrm{L}$ of each primer $(10 \mu \mathrm{M}), 1 \mu \mathrm{L}$ of Taq polymerase (Sigma-Aldrich ${ }^{\circledR}$; St. Louis, MO, USA), and $40 \mu \mathrm{L}$ of $\mathrm{H}_{2} \mathrm{O}$. The thermocycling steps were: initial denaturation at $94{ }^{\circ} \mathrm{C}$ for $2 \mathrm{~min}$ followed by 35 cycles of $94{ }^{\circ} \mathrm{C}$ for $15 \mathrm{~s}, 62{ }^{\circ} \mathrm{C}$ for $15 \mathrm{~s}, 72{ }^{\circ} \mathrm{C}$ for $30 \mathrm{~s}$, followed by a final elongation step of $72{ }^{\circ} \mathrm{C}$ for $10 \mathrm{~min}$. Products were electrophoresed on a $2.5 \%$ agarose gel and visualized with ethidium bromide to ensure that the 3357 primer pair only amplified in 3357 and that the 21882 primer pair only amplified in 21882 (Figure 2). Both primer pairs were tested in 3357 and 21882 genomic DNA as well as with a negative control of water.

\subsection{Standard Curve Development and $q P C R$ Verification}

A unique standard curve was developed for use with the two strain specific primers. The standard curve contained concentrations of $A$. flavus as follows: 10, 5, 1, 0.5, 0.1, 0.05, 0.01, 0.005, 0.001, 0.0005, $0.0001,0.00005 \mathrm{ng} / \mu \mathrm{L}$ of DNA. All serial dilutions of the $5 \mathrm{ng} / \mu \mathrm{L}$ standard point contained $50 \%$ of the target $A$. flavus strain and $50 \%$ of the other A. flavus strain. For example, the $5 \mathrm{ng} / \mu \mathrm{L}$ point in the NRRL 3357 standard curve contained $5 \mathrm{ng} / \mu \mathrm{L}$ of $3357 \mathrm{DNA}$ and $5 \mathrm{ng} / \mu \mathrm{L}$ of $21882 \mathrm{DNA}$ for a total of $10 \mathrm{ng} / \mu \mathrm{L}$ of fungal DNA. All points on the standard curve derived from the $10 \mathrm{ng} / \mu \mathrm{L}$ point contained $100 \%$ of the target fungal strain.

Strain specific primers were tested for efficacy in strain differentiation and quantification in qPCR. The Light Cycler $480^{\circledR}$ instrument from Roche was used with Roche ${ }^{\circledR}$ SYBR green master (Roche Diagnostics $\mathrm{GmbH}$, Mannheim, Germany) for quantification using a reaction volume of $10 \mu \mathrm{L}$ (5 $\mu \mathrm{L}$ of SYBR green master, $0.5 \mu \mathrm{L}$ of $10 \mu \mathrm{M}$ forward and reverse primer, $2 \mu \mathrm{L}$ of $\mathrm{H}_{2} \mathrm{O}$, and $2 \mu \mathrm{L}$ of $10 \mathrm{ng} / \mu \mathrm{L}$ template). The qPCR run was performed as follows: $95^{\circ} \mathrm{C}$ for $10 \mathrm{~min}$ for initial denaturation, followed by 45 cycles of $95^{\circ} \mathrm{C}$ for $10 \mathrm{~s}, 62^{\circ} \mathrm{C}$ for $5 \mathrm{~s}$, and $72{ }^{\circ} \mathrm{C}$ for $10 \mathrm{~s}$. The melting curve had once cycle which included $95^{\circ} \mathrm{C}$ for $10 \mathrm{~s}$ and $65^{\circ} \mathrm{C}$ for $1 \mathrm{~min}$ followed by a gradual heating to $97^{\circ} \mathrm{C}$ with 5 acquisitions per ${ }^{\circ} \mathrm{C}$. A final cooling step at $40^{\circ} \mathrm{C}$ for $10 \mathrm{~s}$ concluded the PCR protocol. The two primer pairs were then tested in duplicate using this protocol by quantifying mixed samples of fungal DNA containing both NRRL 3357 and 21882. Test samples containing $60 \%$ of one fungal strain and $40 \%$ of the other at both $1 \mathrm{ng} / \mu \mathrm{L}$ and $0.1 \mathrm{ng} / \mu \mathrm{L}$ total fungal DNA concentrations were quantified with the 3357 and 21882 primer pairs as well as with primer pair Af2 [16] which quantifies total A. flavus concentration (Table 1).

\subsection{Field Experimental Design, Aflatoxin Analysis and DNA Extraction}

Four single cross hybrids were planted in a randomized complete block design at the R. R. Foil Plant Science Research Center located in city, Mississippi State, MS, USA in 2010 and 2011. 
The genotypes consisted of two susceptible crosses, SC212M $\times$ T173 \& GA209 $\times$ SC212M, and two resistant crosses, Mp313E $\times$ Mo18W \& Mp494 $\times$ Mp717. Ears of each hybrid were inoculated with a toxigenic $A$. flavus fungal strain (NRRL 3357), a non-toxigenic fungal strain (NRRL 21882), water, and co-inoculated with both fungal strains. Inoculation was performed using the side-needle inoculation technique 7 days after mid-silk with a $3.4 \mathrm{~mL}$ suspension containing approximately $3 \times 10^{8}$ conidia of the appropriate $A$. flavus strain [44]. Co-inoculation was performed by inoculating the same ear with the conidial suspension of each strain individually at sites in close proximity using the side-needle technique. Primary ears from 10 plants were harvested approximately 60 days after inoculation and were dried for 7 days at $38^{\circ} \mathrm{C}$.

The ears were then shelled and ground, and aflatoxin accumulation was quantified using the VICAM Aflatest ${ }^{\circledR}$ kit (VICAM, Watertown, MA, USA) using $50 \mathrm{~g}$ of ground material. Total DNA was extracted from $100 \mathrm{mg}$ of the same ground material using the GenoGrinder 2000 (OPS Diagnostics LLC; Lebanon, NJ, USA) and the CTAB extraction method [45]. Total DNA was then quantified and diluted to $10 \mathrm{ng} / \mu \mathrm{L}$ for each sample.

\subsection{Fungal Quantification}

Total fungus for all field samples from both 2010 and 2011 was quantified using the Af2 primer pair. All quantification used an in run standard with concentrations of $A$. flavus DNA ranging from 10, $1,0.1,0.01,0.001$, and $0.0001 \mathrm{ng} / \mu \mathrm{L}$ of DNA. Individual samples were repeated in duplicate. The qPCR conditions for total fungus were as follows: $95^{\circ} \mathrm{C}$ for $10 \mathrm{~min}$ for initial denaturation, followed by 45 cycles of $95^{\circ} \mathrm{C}$ for $10 \mathrm{~s}, 59^{\circ} \mathrm{C}$ for $5 \mathrm{~s}$, and $72^{\circ} \mathrm{C}$ for $10 \mathrm{~s}$. The melting curve had one cycle which included $95^{\circ} \mathrm{C}$ for $10 \mathrm{~s}$ and $65^{\circ} \mathrm{C}$ for $1 \mathrm{~min}$ followed by a gradual heating to $97^{\circ} \mathrm{C}$ with 5 acquisitions per ${ }^{\circ} \mathrm{C}$. A final cooling step at $40^{\circ} \mathrm{C}$ for $10 \mathrm{~s}$ concluded the PCR protocol.

Strain specific quantification was performed using the two strain specific primer pairs to quantify concentrations of 3357 and 21882. As with total fungus, the samples were repeated in duplicate and used an in-run standard curve. The standard curve contained concentrations of $A$. flavus as follows: 10 , $5,1,0.5,0.1,0.05,0.01,0.005,0.001,0.0005,0.0001,0.00005 \mathrm{ng} / \mu \mathrm{L}$ of DNA. For each strain the $100 \%$ standards contained the target strain of interest. The qPCR conditions are the same as those described above in the qPCR validation section.

\subsection{Statistical Analysis}

Aflatoxin concentration values were transformed as $\ln (y+1)$, with $y$ being the aflatoxin concentration, to provide a more normally distributed data set for statistical analysis. Data analysis was performed using the General Linear Model and means for aflatoxin and fungal concentration were compared using Fisher's Protected Least Significant Difference (LSD) at $\alpha=0.05$. SAS ver. 9.4 (SAS Institute, Cary, NC, USA) was used for statistical analysis.

\section{Conclusions}

Biological control agents have been shown to be effective at reducing aflatoxin accumulation in maize and other susceptible crops [9-15,46]. However, much is still not understood about the relationship between maize, toxigenic fungi and the non-toxigenic fungi used as biological control agents. It could not be determined from our study whether the reduction in aflatoxin accumulation in co-inoculated ears was due to competitive exclusion or intraspecific inhibition between the two A. flavus strains. By developing a pair of primers which can be used to successfully, distinctly identify and quantify a toxigenic A. flavus strain (NRRL 3357) and a non-toxigenic strain (NRRL 21882) in co-inoculated ears, we have generated a method that can be used to better understand the relationship between accumulation of $A$. flavus and aflatoxin during co-inoculation. It must be noted that these primers were developed only for these two particular A. flavus strains and thus their ability to differentiate among other toxigenic and non-toxigenic strains is currently unknown. Further studies 
will include determining the usefulness of these primers with other toxigenic and non-toxigenic strains of $A$. flavus as well as with other maize genotypes.

Acknowledgments: The authors would like to thank Norbert Bokros for his assistance with this project.

Author Contributions: J. Erik Mylroie, conceived study design, DNA extraction, sequencing and qPCR, data analysis, and wrote manuscript. Seval Ozkan, DNA extraction, sequencing, and qPCR and manuscript editing. Renuka Shivaji, conceived study design, DNA extraction and sequencing, and manuscript editing. Gary L. Windham, field inoculations and aflatoxin quantification. Michael N. Alpe, field inoculations and sample collections. W. Paul Williams, conceived study design, data analysis contributions and read, edited and approved manuscript.

Conflicts of Interest: The authors declare no conflicts of interest. Mention of trade names or commercial products is soley for the purpose of providing specific information and does not imply recommendation or endorsement by the United States Department of Agriculture.

\section{References}

1. Payne, G.A.; Widstrom, N.W. Aflatoxin in maize. Crit. Rev. Plant Sci. 1992, 10, 423-440. [CrossRef]

2. Castegnaro, M.; McGregor, D. Carcinogenic risk assessment of mycotoxins. Rev. Med. Vet.-Toulouse 1998, 149, 671-678.

3. Robens, J.; Cardwell, K.F. The costs of mycotoxin management in the United States. In Aflatoxin and Food Safety; Abbas, H.K., Ed.; Taylor and Francis: New York, NY, USA, 2005; pp. 1-12.

4. Scott, G.E.; Zummo, N. Registration of Mp313E parental line of maize. Crop Sci. 1990, 30, 1378. [CrossRef]

5. Campbell, K.W.; White, D.G. Evaluation of corn genotypes for resistance to Aspergillus ear rot, kernel infection, and aflatoxin production. Plant Dis. 1995, 79, 1039-1045. [CrossRef]

6. Williams, W.P.; Windham, G.L. Registration of maize germplasm line Mp715. Crop Sci. 2001, 41, 1374-1375. [CrossRef]

7. Williams, W.P.; Windham, G.L. Registration of Mp718 and Mp719 germplasm lines of maize. J. Plant Regist. 2012, 6, 1-3. [CrossRef]

8. Clements, M.J.; White, D.G. Identifying Sources of Resistance to Aflatoxin and Fumonisin Contamination in Corn Grain: History and Progress from the University of Illinois. In Aflatoxin and Food Safety; Abbas, H.K., Ed.; Taylor and Francis: New York, NY, USA, 2005; pp. 395-405.

9. Cotty, P.J.; Bayman, P. Competitive exclusion of a toxigenic strain of Aspergillus flavus by an atoxigenic strain. Phytopathology 1993, 83, 1283-1287. [CrossRef]

10. Cotty, P.J. Influence of field application of an atoxigenic strain of Aspergillus flavus on the populations of A. flavus infecting cotton bolls and on the aflatoxin content of cottonseed. Phytopathology 1994, 84, 1270-1277. [CrossRef]

11. Dorner, J.W. Biological control of aflatoxin crop contamination. In Aflatoxin and Food Safety; Abbas, H.K., Ed.; Taylor and Francis: New York, NY, USA, 2005; pp. 333-352.

12. Dorner, J.W. Biological control of aflatoxin in corn using a nontoxigenic strain of Aspergillus flavus. J. Food Prot. 2009, 72, 201-804.

13. Abbas, H.K.; Zablotowicz, R.M.; Horn, B.W.; Phillips, N.A.; Johnson, B.J.; Jin, X.; Able, C.A. Comparison of major biocontrol strains of non-aflatoxigenic Aspergillus flavus for the reduction of aflatoxins and cyclopiazonic acid in maize. Food Addit. Contam. 2011, 28, 198-208. [CrossRef] [PubMed]

14. Abbas, H.K.; Weaver, M.A.; Horn, B.W.; Carbone, I.; Monacell, J.T.; Shier, W.T. Selection of Aspergillus flavus isolates for biological control of aflatoxins in corn. Toxin Rev. 2011, 30, 59-70. [CrossRef]

15. Weaver, M.A.; Abbas, H.K.; Falconer, L.L.; Allen, T.W.; Pringle, H.C., III; Sciumbato, G.L. Biological control of aflatoxin is effective and economical in Mississippi field trials. Crop Prot. 2015, 69, 52-55. [CrossRef]

16. Mideros, S.X.; Windham, G.L.; Williams, W.P.; Nelson, R.J. Aspergillus flavus biomass in maize estimated by quantitative real-time polymerase chain reaction is strongly correlated with aflatoxin concentration. Plant Dis. 2009, 93, 1163-1170. [CrossRef]

17. Williams, W.P.; Ozkan, S.; Ankala, A.; Windham, G.L. Ear rot, aflatoxin accumulation, and fungal biomass in maize after inoculation with Aspergillus flavus. Field Crops Res. 2011, 120, 196-200. [CrossRef] 
18. Williams, W.P.; Alpe, M.N.; Windham, G.L.; Ozkan, S.; Mylroie, J.E. Comparison of two inoculation methods for evaluating resistance to Aspergillus flavus infection and aflatoxin accumulation. Int. J. Agron. 2013, 2013. [CrossRef]

19. Henry, T.; Iwen, P.C.; Hinrichs, S.H. Identification of Aspergillus species using Internal Transcribed Spacer regions 1 and 2. J. Clin. Microbiol. 2000, 39, 1510-1515.

20. Niessen, L. PCR-based diagnosis and quantification of mycotoxin producing fungi. Int. J. Food Microbiol. 2007, 119, 38-46. [CrossRef] [PubMed]

21. Sardiñas, N.; Vázquez, C.; Gil-Serna, J.; González-Jaén, M.T.; Patiño, B. Specific detection and quantification of Aspergillus flavus and Aspergillus parasiticus in wheat flour by SYBR $^{\circledR}$ Green quantitative PCR. Int. J. Food Microbiol. 2011, 145, 121-125. [CrossRef] [PubMed]

22. Logotheti, M.; Kotsovili-Tseleni, A.; Arsenis, G.; Legakis, N.I. Multiplex PCR for the discrimination of A. fumigatus, A. flavus, A. niger and A. terreus. J. Microbiol. Methods 2009, 76, 209-211. [CrossRef] [PubMed]

23. Ankala, A.; Bolla, B.K.; Shivaji, R.; Williams, W.P.; Wilkinson, J.R. Comparative analysis of the performance of Aspergillus flavus on resistant and susceptible genotypes during infection. Fungal Ecol. 2011, 4, 32-41. [CrossRef]

24. Levin, R.E. PCR detection of aflatoxin producing fungi and its limitations. Int. J. Food Microbiol. 2012, 156, 1-6. [CrossRef] [PubMed]

25. Rodríguez, A.; Rodríguez, M.; Luque, M.I.; Martín, A.; Córdoba, J.J. Real-time PCR assays for detection and quantification of aflatoxin-producing molds in foods. Food Microbiol. 2012, 31, 89-99. [CrossRef] [PubMed]

26. Mahmoud, M.A. Detection of Aspergillus flavus in stored peanuts using real-time PCR and the expression of aflatoxin genes in toxigenic and atoxigenic A. flavus isolates. Foodborne Pathog. Dis. 2015, 12, 289-296. [CrossRef] [PubMed]

27. Chang, P.K.; Horn, B.W.; Dorner, J.W. Sequence breakpoints in the aflatoxin biosynthesis gene cluster and flanking regions in nonaflatoxigenic Aspergillus flavus isolates. Fungal Genet. Biol. 2005, 42, 914-923. [CrossRef] [PubMed]

28. White, T.J.; Bruns, T.D.; Lee, S.B.; Taylor, J.W. Amplification and direct sequencing of fungal ribosomal RNA genes for phylogenetics. PCR Protoc.: Guide Methods Appl. 1990, 18, 315-322.

29. Rigó, K.; Varga, J.; Tóth, B.; Téren, J.; Mesterházy, Á.; Kozakiewicz, Z. Evolutionary relationships within Aspergillus section Flavi based on sequences of the intergenic transcribed spacer regions and the 5.8 S rRNA gene. J. Gen. Appl. Microbiol. 2002, 48, 9-16. [CrossRef] [PubMed]

30. Mohankumar, M.; Vijayasamundeeswari, A.; Karthikeyan, M.; Mathiyazhagan, S.; Paranidharan, V.; Velazhahan, R. Analysis of molecular variability among isolates of Aspergillus flavus by PCR-RFLP of the ITS regions of rDNA. J. Plant Prot. Res. 2010, 50, 446-451. [CrossRef]

31. Dorner, J.W.; Lamb, M.C. Development and commercial use of afla-guard ${ }^{\circledR}$, an aflatoxin biocontrol agent. Mycotoxin Res. 2006, 22, 33-38. [CrossRef] [PubMed]

32. Conserved Primer Sequences for PCR Amplification and Sequencing from Nuclear Ribosomal RNA. Available online: http://sites.biology.duke.edu/fungi/mycolab/primers.htm (accessed on 15 August 2012).

33. Cotty, P.J. Effect of atoxigenic strains of Aspergillus flavus on aflatoxin contamination of developing cottonseed. Plant Dis. 1990, 74, 233-235. [CrossRef]

34. Dorner, J.W.; Cole, R.J.; Wicklow, D.T. Aflatoxin reduction in corn through field application of competitive fungi. J Food Prot. 1999, 62, 650-656. [PubMed]

35. Abbas, H.K.; Zablotowicz, R.M.; Bruns, H.A.; Abel, C.A. Biocontrol of aflatoxin in corn by inoculation with non-aflatoxigenic Aspergillus flavus isolates. Biocontrol Sci. Technol. 2006, 16, 437-449. [CrossRef]

36. Chang, P.K.; Hua, S.S.T. Nonaflatoxigenic Aspergillus flavus TX9-8 competitively prevents aflatoxin accumulation by A. flavus isolates of large and small sclerotial morphotypes. Int. J. Food Microbiol. 2007, 114, 275-279. [CrossRef] [PubMed]

37. Ehrlich, K. Effect on aflatoxin production of competition between wild-type and mutant strains of Aspergillus parasiticus. Mycopathologia 1987, 97, 93-96. [CrossRef] [PubMed]

38. Wicklow, D.T.; Bobell, J.R.; Palmquist, D.E. Effect of intraspecific competition by Aspergillus flavus on aflatoxin formation in suspended disc culture. Mycol. Res. 2003, 107, 617-623. [CrossRef] [PubMed]

39. Wicklow, D.T.; Horn, B.W. Association between vegetative compatibility and aflatoxin production by Aspergillus species during intraspecific competition. Mycoscience 2007, 48, 267-273. [CrossRef] 
40. Huang, C.; Jha, A.; Sweany, R.; DeRobertis, C.; Damann, K.E., Jr. Intraspecific aflatoxin inhibition in Aspergillus flavus is thigmoregulated, independent of vegetative compatibility group and is strain dependent. PLoS ONE 2011, 6. [CrossRef] [PubMed]

41. Damann, K.E., Jr. Atoxigenic Aspergillus flavus biological control of aflatoxin contamination: What is the mechanism? World Mycotoxin J. 2014, 8, 235-244. [CrossRef]

42. Paterson, A.H.; Brubaker, C.L.; Wendel, J.F. A rapid method for extraction of cotton (Gossypium spp.) genomic DNA suitable for RFLP or PCR analysis. Plant Mol. Biol. Rep. 1993, 11, 122-127. [CrossRef]

43. Untergrasser, A.; Cutcutache, I.; Koressaar, T.; Ye, J.; Faircloth, B.C.; Remm, M.; Rozen, S.G. Primer3-New capabilities and interfaces. Nucleic Acids Res. 2012, 40, e115, Primer3(v.0.40). Available online: http://bioinfo.ut.ee/primer3-0.4.0/ (accessed on 1 December 2012). [CrossRef] [PubMed]

44. Zummo, N.; Scott, G.E. Evaluation of field inoculation techniques for screening maize genotypes against kernel infection by Aspergillus flavus in Mississippi. Plant Dis. 1989, 73, 313-316. [CrossRef]

45. Saghai-Maroof, M.A.; Soliman, K.M.; Jorgensen, R.A.; Allard, R.W. Ribosomal DNA spacer-length polymorphisms in barley: Mendelian inheritance, chromosomal location, and population dynamics. Proc. Natl. Acad. Sci. USA 1984, 81, 8014-8018. [CrossRef] [PubMed]

46. Brown, R.L.; Cotty, P.J.; Cleveland, T.E. Reduction in aflatoxin content of maize by atoxigenic strains of Aspergillus flavus. J. Food Prot. 1991, 54, 623-626.

(C) 2016 by the authors; licensee MDPI, Basel, Switzerland. This article is an open access article distributed under the terms and conditions of the Creative Commons by Attribution (CC-BY) license (http:/ / creativecommons.org/licenses/by/4.0/). 